\title{
Situação epidemiológica da brucelose bovina no Estado de Santa Catarina
}

\author{
[Epidemiological situation of bovine brucellosis in the State of Santa Catarina, Brazil] \\ S. Sikusawa ${ }^{1}$, M. Amaku1, R.A. Dias ${ }^{1}$, J.S. Ferreira Neto ${ }^{1}$, C. Martins ${ }^{2}$, V.S.P. Gonçalves ${ }^{3}$, \\ V.C.F. Figueiredo ${ }^{4}$, J.R. Lôbo ${ }^{4}$, F. Ferreira ${ }^{1 *}$ \\ ${ }^{1}$ Faculdade de Medicina Veterinária e Zootecnia - USP \\ Av. Prof. Dr. Orlando Marques de Paiva, 87 \\ 05508-270 - São Paulo, SP \\ ${ }^{2}$ Companhia Integrada de Desenvolvimento de Santa Catarina-CIDASC - Florianópolis, SC \\ ${ }^{3}$ Faculdade de Agronomia e Medicina Veterinária - UnB - Brasília, DF \\ ${ }^{4}$ Departamento de Saúde Animal - SDA-MAPA - Brasília, DF
}

\begin{abstract}
RESUMO
Realizou-se um estudo para caracterizar a situação epidemiológica da brucelose bovina no Estado de Santa Catarina. O Estado foi estratificado em cinco circuitos produtores. Em cada circuito produtor foram amostradas aleatoriamente cerca de 300 propriedades e, dentro dessas, foi escolhido, de forma aleatória, um número pré-estabelecido de animais, dos quais foi obtida uma amostra de sangue. No total foram amostrados 7801 animais, provenientes de 1586 propriedades. O protocolo de testes utilizado foi o da triagem com o teste do antígeno acidificado tamponado e o reteste dos positivos com o do 2mercaptoetanol. $\mathrm{O}$ rebanho foi considerado positivo se pelo menos um animal foi reagente às duas provas sorológicas. As prevalências de focos e de animais infectados no Estado foram de 0,32\% [0,10-0,69\%] e $0,06 \%$ [0,0-0,17\%], respectivamente. A prevalência de focos nos circuitos pecuários foram: circuito 1 , $0,33 \%$ [0,0-0,99\%]; circuito $2,0,33 \%$ [0,0-1,0\%]; circuito $3,0,25 \%$ [0,0-0,75\%]; circuito $4,0,66 \%$ [0,08-1,84\%] e circuito $5,0,33 \%[0,0-1,0 \%]$.
\end{abstract}

Palavras-chave: bovino, brucelose, prevalência, Santa Catarina

\begin{abstract}
A study to characterize the brucellosis epidemiological situation in the State of Santa Catarina was carried out. The State was divided into five regions. Three hundred herds were randomly sampled in each region and a pre-established number of animals were sampled in each of these herds. A total of 7,801 serum samples from 1,586 herds were collected. In each herd, it was applied an epidemiological questionnaire regarding herd features and also husbandry and sanitary practices that could be associated with risk of infection. The serum samples were screened for antibodies to Brucella spp. by the Rose-Bengal Test (RBT), and all RBT-positive sera re-tested by the 2-mercaptoethanol test (2-ME). The herd was considered positive if at least one animal was positive on both RBT and 2-ME tests. The prevalences of infected herds and animals in Santa Catarina State were, respectively: 0.32\% [0.10$0.69 \%]$ and $0.06 \%[0.0-0.17 \%]$. The prevalence of infected herds in the regions were: region 1, 0.33\% [0.0-0.99\%]; region 2, $0.33 \%[0.0-1.0 \%]$; region 3, $0.25 \%[0.0-0.75 \%]$; region 4, $0.66 \%[0.08-$ $1.84 \%]$; and region $5,0.33 \%[0.0-1.00 \%]$.
\end{abstract}

Keywords: cattle, brucellosis, prevalence, Santa Catarina, Brazil

Recebido em 27 de março de 2009

Aceito em 23 de setembro de 2009

* Autor para correspondência (corresponding author)

E-mail: fernando@vps.fmvz.usp.br 


\section{INTRODUÇÃO}

O Estado de Santa Catarina ocupa uma pequena área geográfica $(1,12 \%)$ do País, sendo uma das menores unidades federativas. Sua população humana representa $3,2 \%$ da população nacional (cerca de cinco milhões de habitantes), e é o segundo melhor índice de desenvolvimento humano entre as unidades federativas. $\mathrm{O}$ rebanho bovino pouco expressivo $(1,6 \%$ do rebanho nacional, ou seja, cerca de três milhões de cabeças) contrasta com o grande número de propriedades de criação de bovinos $(9,1 \%$ do total nacional). A pecuária de corte não tem importância no cenário nacional, mas o Estado é o principal produtor de suínos e o segundo principal produtor de aves. O sucesso da atividade pecuária deve-se a um eficiente sistema de integração entre empresas agroindustriais e produtores rurais. Esta cadeia produtiva responde por cerca de $24,2 \%$ das exportações de carnes do País.

Santa Catarina é um dos principais produtores de alimentos do Brasil. O setor agrícola representa $14,3 \%$ do PIB estadual devido à qualidade do solo, alta produtividade e distribuição fundiária equilibrada. A agricultura familiar em Santa Catarina representa mais de $90 \%$ da população rural. Estas 180.000 famílias de agricultores ocupam somente $41 \%$ da área dos estabelecimentos agrícolas, mas são responsáveis por mais de $70 \%$ do valor da produção agrícola e pesqueira do Estado. Este cenário faz com que o Estado apresente uma série de peculiaridades, quando comparado aos demais estados. Pequenos rebanhos, em pequenas propriedades, realizam poucas trocas comerciais que facilitam o controle de doenças infecciosas, principalmente a brucelose.

Com a implantação do Programa Nacional de Controle e Erradicação da Brucelose e Tuberculose (PNCEBT; Brasil, 2006) houve a necessidade de um levantamento nacional da prevalência dessas enfermidades de modo a conhecer a sua situação epidemiológica. Os objetivos deste trabalho foram estimar a prevalência de focos e de animais soropositivos para brucelose bovina, identificar os fatores de risco para a doença e fornecer subsídios para melhor implantação e gestão do PNCEBT.

\section{MATERIAL E MÉTODOS}

O estudo foi planejado por técnicos do Ministério da Agricultura, Pecuária e Abastecimento, da Universidade de São Paulo e da Universidade de Brasília, em colaboração com técnicos da Companhia Integrada de Desenvolvimento Agrícola de Santa Catarina (CIDASC). O trabalho de campo foi realizado por técnicos da CIDASC, no período de outubro a dezembro de 2001.

Para que fossem conhecidas as diferenças regionais nos parâmetros epidemiológicos da brucelose bovina e bubalina, o Estado de Santa Catarina foi dividido em cinco circuitos produtores de bovinos, levando-se em consideração os diferentes sistemas de produção, práticas de manejo, finalidades de exploração, tamanho médio de rebanhos e sistemas de comercialização. A divisão do Estado em circuitos produtores também levou em conta a capacidade operacional e logística do serviço veterinário oficial do Estado para a realização das atividades de campo, baseando-se nas áreas de atuação das suas unidades regionais.

Em cada circuito produtor, estimou-se a prevalência de propriedades infectadas pela brucelose bovina e a de animais soropositivos por meio de um estudo amostral em dois estágios, dirigido para detectar focos da doença. No primeiro estágio, sorteou-se, aleatoriamente, um número pré-estabelecido de propriedades com atividade reprodutiva (unidades primárias de amostragem). No segundo, sorteou-se um número pré-estabelecido de fêmeas bovinas com idade igual ou superior a 24 meses (unidades secundárias de amostragem).

Nas propriedades rurais onde existia mais de um rebanho, foi escolhido o rebanho bovino de maior importância econômica, no qual os animais estavam submetidos ao mesmo manejo, ou seja, sob os mesmos fatores de risco. A escolha da unidade primária de amostragem foi aleatória, baseada no cadastro de propriedades rurais com atividade reprodutiva de bovinos. A propriedade sorteada que, por motivos vários, não pôde ser visitada, foi substituída por outra, nas proximidades e com as mesmas características de produção. O tamanho da amostra por circuito foi estimado pela fórmula para amostras simples aleatórias proposta por 
Noordhuizen et al. (1997). Os cálculos de prevalência aparente ponderada e o respectivo intervalo de confiança foram realizados com o auxílio do programa STATA e por meio do método de Monte Carlo. Os parâmetros adotados para o cálculo foram: nível de confiança de $95 \%$, prevalência esperada, fixada em $25 \%$ e erro de $5 \%$. A capacidade operacional e financeira do serviço veterinário oficial do Estado também foi levada em consideração para a determinação do tamanho da amostra por circuito.

O planejamento amostral para as unidades secundárias visou estimar um número mínimo de animais a serem examinados dentro de cada propriedade de forma a permitir a sua classificação como foco ou não foco de brucelose. Para tanto, foi utilizado o conceito de sensibilidade e especificidade agregadas. Para efeito dos cálculos foram adotados os valores de $95 \%$ e $99,5 \%$, respectivamente, para a sensibilidade e a especificidade do protocolo de testes utilizado (Fletcher et al., 1998) e 20\% para a prevalência estimada. Nesse processo foi utilizado o programa Herdacc versão 3 e o tamanho da amostra escolhido foi aquele que permitiu valores de sensibilidade e especificidade de rebanho iguais ou superiores a $90 \%$. Assim, nas propriedades com até 99 fêmeas com idade superior a 24 meses, foram amostrados 10 animais e nas com 100 ou mais fêmeas com idade superior a 24 meses, 15 animais. A escolha das fêmeas dentro das propriedades foi casual sistemática.

O protocolo de testes foi composto pela triagem com o teste do antígeno acidificado tamponado ou teste Rosa Bengala, seguida do reteste dos positivos com o teste do 2-mercaptoetanol, de acordo com as recomendações do PNCEBT (Brasil, 2006). Os testes foram realizados nos laboratórios regionais da CIDASC.
A propriedade foi considerada positiva quando se detectou pelo menos um animal positivo. As propriedades que apresentaram animais com resultado sorológico inconclusivo, sem nenhum positivo, foram classificadas como suspeitas e excluídas das análises. $\mathrm{O}$ mesmo tratamento foi dado aos animais com resultados sorológicos inconclusivos.

Considerando-se que a amostra de unidades primárias em cada circuito produtor foi aleatória sistemática (Cochran, 1997), a prevalência aparente de focos de brucelose foi calculada utilizando-se como parâmetros o número de focos e o número de propriedades amostradas (Dean et al., 1994). Os parâmetros utilizados no cálculo da prevalência aparente de focos foram o status da propriedade (foco ou livre da brucelose), o circuito a que pertence cada propriedade e o peso estatístico de cada propriedade amostrada no circuito, calculado pela razão entre o número de propriedades com atividade reprodutiva e o número de propriedades amostradas em cada circuito produtor.

Os cálculos das prevalências de focos e de animais no Estado e das prevalências de animais dentro das regiões foram feitos de forma ponderada, conforme preconizado por Dohoo et al. (2003).

O peso de cada propriedade no cálculo da prevalência de focos no Estado foi dado por

$$
\mathrm{P}_{1}=\frac{\text { propriedades na região }}{\text { propriedades amostradas na região }}
$$

O peso de cada animal no cálculo da prevalência de animais no Estado foi dado por:

$$
\mathrm{P}_{2}=\frac{\text { fêmeas } \geq 12 \text { meses na propriedade }}{\text { fêmeas } \geq 12 \text { meses amostradas na propriedade }} \times \frac{\text { fêmeas } \geq 12 \text { meses na região }}{\text { fêmeas } \geq 12 \text { meses nas propriedades amostradas }}
$$

$\mathrm{Na}$ expressão acima, o primeiro termo refere-se ao peso de cada animal no cálculo das prevalências de animais dentro das regiões.

Em cada propriedade amostrada, além da coleta de sangue para a sorologia, foi também aplicado um questionário epidemiológico, elaborado para obter informações sobre o tipo de exploração e as práticas de manejo empregadas.

Todas as informações geradas pelo trabalho de campo e de laboratório foram inseridas em um banco de dados específico, utilizado nas análises epidemiológicas. 


\section{RESULTADOS E DISCUSSÃO}

O Estado foi dividido em cinco circuitos, considerando as características regionais da produção pecuária (Fig. 1). Na Tab. 1, apresentam-se os dados censitários e o tamanho da amostra estudada em cada um dos circuitos produtores.

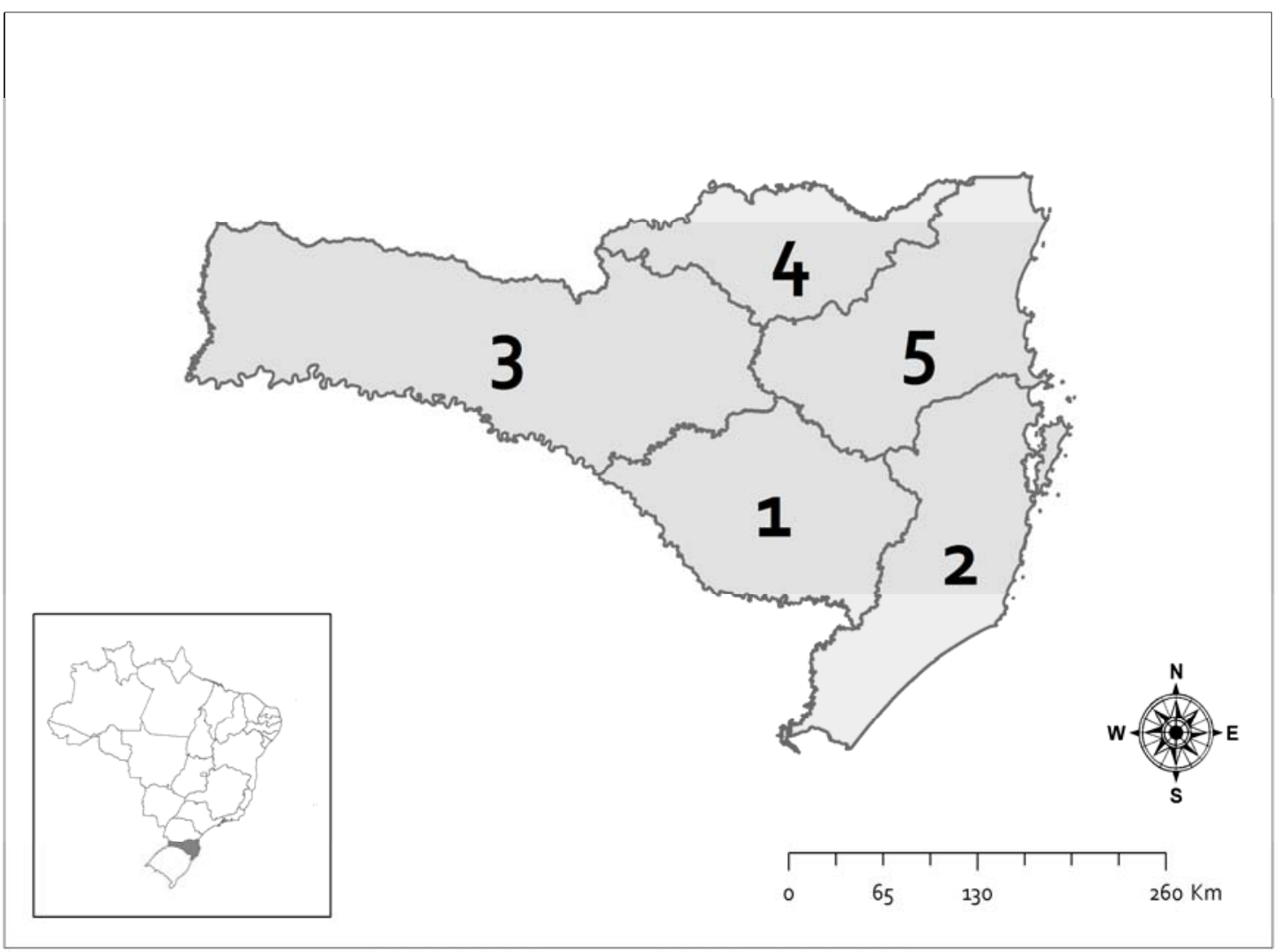

Figura 1. Mapa do Estado de Santa Catarina com a divisão em circuitos produtores. No detalhe, a localização da Unidade Federativa no Brasil.

Tabela 1. Dados censitários da população bovina do Estado de Santa Catarina, segundo o circuito produtor

\begin{tabular}{lcccc}
$\begin{array}{c}\text { Circuito } \\
\text { produtor }\end{array}$ & $\begin{array}{c}\text { Total de propriedades } \\
\text { com atividade } \\
\text { reprodutiva }\end{array}$ & $\begin{array}{c}\text { Propriedades } \\
\text { amostradas }\end{array}$ & $\begin{array}{c}\text { Total de } \\
\text { fêmeas com } \\
\text { idade } \geq 24 \\
\text { meses }\end{array}$ & $\begin{array}{c}\text { Fêmeas } \\
\text { amostradas }\end{array}$ \\
\hline 1- Sul & 13.024 & 299 & 225.823 & 1.920 \\
2- Leste & 30.635 & 298 & 163.609 & 1.253 \\
3- Oeste & 80.754 & 396 & 693.752 & 2.171 \\
4- Norte & 11.113 & 297 & 86.319 & 1.181 \\
5- Nordeste & 33.383 & 296 & 197.896 & 1.276 \\
Total & 168.909 & 1.586 & 1.367 .399 & 7.801 \\
\hline
\end{tabular}


A mediana do número de fêmeas com idade igual ou superior a 24 meses por propriedade no Estado foi de 3,00 [2,00-7,25], havendo homogeneidade entre os circuitos. Nos circuitos de 1 a 5 as medianas foram, respectivamente: $7,00[3,00-16,50], 2,00[1,00-5,00], 4,00[2,00-$ $8,00], 2,00[1,00-5,00]$ e $3,00[1,00-5,00]$.

$\mathrm{Na}$ Tab. 2, mostram-se os resultados de prevalência de focos no Estado e nos circuitos produtores. A prevalência foi estimada utilizando-se a distribuição beta e o intervalo de confiança calculado por meio do método de Monte Carlo. Estes valores permitiram estimar o número esperado de propriedades-foco em cada circuito o que permitiu estimar a prevalência de focos no Estado. A Tab. 3 traz a prevalência de animais.

Tabela 2. Prevalência de focos de brucelose bovina na propriedade, segundo o circuito produtor, no Estado de Santa Catarina, 2004

\begin{tabular}{|c|c|c|c|c|}
\hline \multirow{2}{*}{ Circuito produtor } & \multicolumn{2}{|c|}{ Propriedades } & \multirow{2}{*}{ Prevalência (\%) } & \multirow{2}{*}{ IC $(95 \%)$} \\
\hline & Testadas & Positivas & & \\
\hline $1-\mathrm{Sul}$ & 299 & 0 & $0,33^{1}$ & {$[0,00-0,99]^{2}$} \\
\hline 2- Leste & 298 & 0 & $0,33^{1}$ & {$[0,00-1,00]^{2}$} \\
\hline 3- Oeste & 396 & 0 & $0,25^{1}$ & {$[0,00-0,75]^{2}$} \\
\hline 4- Norte & 297 & 1 & $0,66^{1}$ & {$[0,08-1,84]^{2}$} \\
\hline 5- Nordeste & 296 & 0 & $0,33^{1}$ & {$[0,00-1,00]^{2}$} \\
\hline Total & 1.586 & 1 & 0,32 & {$[0,10-0,69]$} \\
\hline
\end{tabular}

${ }^{1}$ Calculado utilizando a distribuição beta.

${ }^{2}$ Calculado utilizando o método de Monte Carlo e distribuição beta.

IC: intervalo de confiança.

Tabela 3. Prevalência de animais sororreagentes para brucelose, segundo o circuito produtor, no Estado de Santa Catarina, 2004

\begin{tabular}{lcccc}
\hline \multirow{2}{*}{ Circuito produtor } & \multicolumn{2}{c}{ Animais } & Prevalência (\%) & IC (95\%) \\
\cline { 2 - 3 } & Testados & Positivos & & \\
\hline 1- Sul & 1.920 & 0 & (sem observações) & - \\
2- Leste & 1.253 & 0 & (sem observações) & - \\
3- Oeste & 2.171 & 0 & (sem observações) & - \\
4- Norte & 1.181 & 2 & 0.89 & {$[0,00-2,58]$} \\
5- Nordeste & 1.276 & 0 & (sem observações) & - \\
Total & 7.801 & 2 & 0,06 & {$[0,00-0,17]$} \\
\hline
\end{tabular}

IC: intervalo de confiança.

A prevalência de focos de brucelose para o Estado de Santa Catarina foi de 0,32\% [0,10$0,69 \%$ ] (Tab. 2) e a prevalência de animais soropositivos no Estado de 0,06\% [0,0-0,17\%] (Tab. 3). Estes resultados são semelhantes aos obtidos em dois estudos anteriores realizados no Estado de Santa Catarina, o primeiro em 1975, e o segundo em 1996, que estimaram a prevalência em $0,2 \%$ e $0,6 \%$, respectivamente (Paulin e Ferreira Neto, 2003). Isso demonstra que o Estado tem, historicamente, baixa prevalência de brucelose, provavelmente em virtude da boa estruturação dos serviços oficiais aliada às características produtivas do Estado, constituído por pequenas propriedades com poucos animais (mediana de fêmeas $\geq 24$ meses $=3,00$ ). $\quad$ É importante destacar que o Estado de Santa Catarina nunca teve a vacinação contra a brucelose como ação obrigatória e, portanto, acredita-se que a baixa prevalência seja consequência da pequena movimentação de animais entre as propriedades e da realização de testes diagnósticos, com subsequente sacrifício dos positivos, quando ela ocorre. 
Em relação ao intervalo de confiança para a prevalência de focos, em virtude de apenas um circuito apresentar uma única propriedade-foco e, portanto, todos os outros serem constituídos apenas por propriedades negativas, optou-se por utilizar a distribuição beta para o cálculo de prevalência em cada circuito, sendo o intervalo de confiança estimado por meio do método de Monte Carlo. Esse procedimento pode superestimar a prevalência de focos e o intervalo de confiança, porém é preferido e, portanto, mais conservador que os métodos tradicionais que, neste caso, subestimariam a prevalência, uma vez que, em cada estrato onde não se detectaram casos, a prevalência calculada seria zero, com intervalo de confiança também igual a zero. Desse modo, a ponderação para o cálculo de prevalência de focos no Estado produziria apenas a diluição da prevalência verificada no estrato 4 . Para o caso da prevalência de animais positivos não foi possível adotar os mesmos procedimentos e utilizou-se a estimativa produzida pelo STATA.

Esses dados mostram que o Estado de Santa Catarina caracteriza-se por prevalências muito baixas tanto de focos quanto de animais, reunindo condições para a implementação de estratégias de erradicação da brucelose. Em decorrência desse fato, o Ministério da Agricultura, Pecuária e Abastecimento excluiu o Estado da obrigatoriedade de vacinar fêmeas entre três e oito meses com a amostra B19.

A implementação de estratégias de erradicação envolve a proibição da vacinação, já providenciada, e a estruturação de sistema de vigilância para detecção e extinção dos focos residuais, conforme descrito por Paulin e Ferreira Neto (2003).

A detecção dos focos poderá ser feita de várias formas: pesquisa de anticorpos no leite, sorodiagnóstico de reprodutores descartados em abatedouro, sorodiagnóstico para movimentar animais de reprodução, estudos por amostragem, investigação de denúncia ou rumor, busca ativa nos produtores informais e investigação de casos de abortamento bovino e de brucelose humana. Adicionalmente, poderão ser investigadas as propriedades que mantêm relações comerciais com os focos. A reação seria sempre o saneamento do foco por meio de rotina de testes indiretos com sacrifício de positivos. A decisão de adotar ou não duas estratégias no Estado dependerá da definição clara dessas estratégias tendo em vista a capacidade operacional do Serviço Veterinário Oficial.

Para o Estado recomenda-se somente implementar estratégia de erradicação.

\section{AGRADECIMENTOS}

À FAPESP, ao CNPq, à CIDASC e ao MAPA pelo apoio financeiro.

\section{REFERÊNCIAS BIBLIOGRÁFICAS}

BRASIL. Ministério de Agricultura, Pecuária e Abastecimento. Programa Nacional de Controle e Erradicação da Brucelose e da Tuberculose Animal (PNCEBT): Manual técnico. Brasília, 2006. 184p.

COCHRAN, W.G. Sampling techniques. 3.ed. New York: John Wiley, 1997. 428p.

DEAN, A.G.; DEAN, J.A.; COLOMBIER, D. et al. Epi-Info, Version 6: A word processing database, and statistics program for epidemiology on microcomputers. Atlanta: CDC, 1994. 601p.

DOHOO, I.; MARTIN, W.; STRYHN, H. Veterinary epidemiologic research. Charlottetown, Canadá: Atlantic Veterinary College, 2003. 706p.

FLETCHER, R.H.; FLETCHER, S.W.; WAGNER, E.H. Clinical epidemiology: The essentials. 2.ed. Baltimore: Williams \& Wilkins, 1998. 246p.

NOORDHUIZEN, J.P.T.M.; FRANKENA, K.; VAN DER HOOFD, C.M. et al. Application of quantitative methods in veterinary epidemiology. Wageningen: Wageningen Press, 1997. 445p.

PAULIN, L.M.; FERREIRA NETO, J.S. $O$ combate à brucelose bovina: Situação brasileira. Jaboticabal: FUNEP, 2003. 154p. 